\title{
Kekongruenan untuk Hasil Bagi Fermat Modulo
}

Try Azisah Nurman

Universitas Islam Negeri Alauddin Makassar

ABSTRAK, Artikel ini difokuskan pada modulo dengan sisa, berupa negatif $\boldsymbol{p}$ untuk bilangan prima ganjil positif, berdasarkan teorema binomial dan identitas pascal yang diketahui. Dari identitas persamaan ini, ruas ruas kanan dihubungkan dengan bilangan harmonik dan bilangan Bernoulli, untuk bilangan bilangan harmonik yang dipakai adalah persamaan-persamaan kekongruenannya untuk modulo $\boldsymbol{p}, \boldsymbol{p}^{2} \boldsymbol{p}^{3}$ dan $\boldsymbol{p}^{4}$, sedangkan bilangan harmonik $\mathrm{H}_{\mathrm{n}}$ dan $\mathrm{H}_{\mathrm{n}, \mathrm{m}}$ untuk $\mathrm{n} \geq 1, \mathrm{~m} \geq 1$ berbeda, begitu pula untuk bilangan Bernoulli $B_{n}$, yaitu persamaan-persamaan dalam bentuk kekongruenan yang dipakai. Dengan menyamakan persamaan-persamaan ini dan kemudian dihubungkan dengan teorema Binomial dan identitas pascal, maka hasil yang peroleh mengandung bilangan harmonik dan bilangan bernoulli untuk kekongruenan modulo $\boldsymbol{p}^{4}$ dengan sisa berupa negatif untuk $\boldsymbol{p}$ suatu bilangan prima ganjil positif.

Kata Kunci: Identitas Pascal, Kekongruenan, Teorema Kecil Fermat, Bilangan Bernoulli, dan Bilangan Harmonik

\section{PENDAHULUAN}

Sebelum mengenal perhitungan angka dan bilangan, cara menghitung beberapa kepemilikan pada saat itu menggunakan beberapa lambang (simbol) untuk membandingkan banyak sedikitnya suatu kepemilikan, dalam perhitungannya mula-mula menggunakan kerikil, kemudian simpul pada tali lalu menggunakan jari tangan atau ranting pohon. Semakin berkembang dan berjalannya waktu, semakin berkembang pula cara menghitungnya seperti sampai pada waktu sekarang, dan sampai sekarang ilmu tersebut disebut ilmu hitung (ilmu matematika).

Dimasa sekarang ilmu hitung atau biasa disebut matematika memiliki beberapa cabang ilmu,dalam artian saling berhubungan antara ilmu yang satu dengan yang lain, salah satunya seperti ilmu matematika dengan ilmu kimia. Ilmu matematika pula memiliki pokok bahasan yang banyak, salah satunya adalah pokok bahasan teori bilangan. Bilangan merupakan salah satu cabang ilmu matematika murni yang mempelajari sifat-sifat bilangan bulat.

Dalam teori bilangan, bilangan bulat sangat perlu dipelajari karena dengan bilangan bulat banyak mengenai tentang konsep bilangan seperti bilangan prima, bilangan ganjil, bilangan genap, bilangan cacah dan masih banyak lagi, terlebih lagi dalam artikel ini difokuskan pada bilangan prima. Yang sangat menarik dikaji pada konsep kekongruenan dengan sifat keterbagian yang berkaitan dengan hasil bagi dan sisa dengan menggunakan salah satu teorema yang dinamakan "teorema fermat"

\section{TINJAUAN PUSTAKA}

\section{Bilangan Bulat}

\section{Definisi 1: (definisi ketunggalan suatu bilangan)}

Jika $n$ bilangan bulat, maka $-n$ didefinisikan tunggal sehingga;

$$
n+(-n)=(-n)+n=0
$$

Definisi 1 menyatakan bahwa secara umum, $-n$ adalah satu-satunya bilangan, yang bila ditambah dengan $n$ akan menghasilkan 0 , dimana $n$ adalah bilangan asli. Bilangan $-n$ disebut "invers tambah (aditif) dari $n$ " atau "lawan dari $n$. Jika $-n$ adalah invers tambah dari $n$ maka $n$ adalah invers tambah dari $-n$. Seandainya $n=0$ (nol) dan lawan dari 0 adalah -0 dengan $0+(-0)=0$, tidak termasuk dalam definisi 1 karena 0 sendiri mempunyai sifat $0+$ $0=0{ }^{[11]}$

\section{Definisi 2: (definisi bilangan bulat)}

Misalkan $\mathbb{Z}$ menyatakan anggota himpunan suatu bilangan bulat maka

$$
\mathbb{Z}=\{\boldsymbol{y} \mid-\infty<\boldsymbol{y}<\infty,\}
$$

Beberapa sifat-sifat dalam bilangan bulat:

\section{Sifat tertutup}

2. Sifat komitatif

3. Sifat asosiatif

4. Sifat distributif

5. Unsur identitas

6. Sifat lainnya,

a. Refleksi

b.Simetris 
c. Transitif

d.Subtitusi

\section{Bilangan Prima}

\section{Definisi 3: (definisi bilangan prima)}

Bilangan bulat $\boldsymbol{p}>\mathbf{1}$ disebut bilangan prima bilamana tidak ada pembagi $\boldsymbol{d}$ terhadap $\boldsymbol{p}$ yang memenuhi syarat $\mathbf{1}<\boldsymbol{d}<\boldsymbol{p}$. Dengan perkataan lain, bilangan prima adalah bilangan asli yang lebih besar dari satu, yang faktor pembaginya adalah satu dan bilangan itu sendiri. Sebuah bilangan bulat $\boldsymbol{p}>\mathbf{1}$ yang bukan bilangan prima disebut bilangan komposit (tersusun). ${ }^{[11]}$

Banyak matematikawan mencoba mencari rumus untuk menentukan bilangan prima, akan tetapi rumus yang mereka temukan tidak membuahkan hasil yang puas. Rumus yang masih dipakai untuk menentukan bilangan prima tersebut sebagiannya adalah;

a) Bilangan prima Sophie Germain, yaitu bilangan prima dengan rumus $2 p+1$, misalnya 23 adalah prima Sophie Germain karena $(2 \times 23)+1=47$ dan bilangan 47 juga merupakan bilangan prima. Sehingga bilangan ini diberi nama sesuai dengan nama matematikawan asal Prancis "Marie Sophie Germain".

b) Teorema fermat, "jika $p$ adalah bilangan prima, maka untuk semua bilangan bulat $a$, $a^{p}=a(\bmod p)$ ". Ini berarti, jika diambil sembarang bilangan a kemudian di kalikan dengan dirinya sendiri sebanyak $p$ kali, dan dikurangi dengan $a$, hasilnya akan habis dibagi oleh $p$.

Faktor Persekutuan Terbesar dan Kelipatan Persekutuan Terkecil

\section{Definisi 4.a: (Faktor Persekutuan)}

Bila $\boldsymbol{d} \mid \boldsymbol{a}$ dan $\boldsymbol{d} \mid \boldsymbol{b}$ maka $\boldsymbol{d}$ disebut faktor persekutuan dari $\boldsymbol{a}$ dan $\boldsymbol{b}$. Sebagai ilustrasi, 1 merupakan faktor persekutuan dari setiap pasangan bilangan bulat. Bila adan btidak keduanya $\mathbf{0}$ maka faktor persekutuannya tidak akan melebihi $|\boldsymbol{a}|$ dan juga $|\boldsymbol{b}|$.

Definisi 4.b: (Faktor Persekutuan Terbesar)
Bilangan paling besar diantara semua faktor persekutuan tersebut disebut faktor persekutan terbesar (FPB) atau great common divisor $(\boldsymbol{g c d})$. Dalam hal ini $\boldsymbol{d}$ disebut faktor persekutuan terbesar dari $\boldsymbol{a}$ dan dari $\boldsymbol{b}$, atau ditulis $\boldsymbol{d}=\boldsymbol{g c d}(\boldsymbol{a}, \boldsymbol{b})$, atau $F P B(\boldsymbol{a}, \boldsymbol{b})=\boldsymbol{d}$, tetapi biasa ditulis $(\boldsymbol{a}, \boldsymbol{b})=\boldsymbol{d}$.

Definisi 4.b di atas dengan $(a, b)=d$ dapat dikarakterisasikan oleh;

1. $d \mid a$ dan $d \mid b$ (ini berarti $d$ faktor persekutuan daria dan darib).

2. Bila ada $c$ dengan $c \mid a$ dan $c \mid b$ maka $c \leq d$, ini berarti $d$ faktor persekutuan terbesar.

Definisi 5: (bilangan prima relatif)

Untuk tiga bilangan bulat $a, b$ dan $c$ dikatakan saling prima relatif jika $(a, b, c)=1$.

Algoritma Euclidean adalah algoritma untuk mencari FPB dari dua buah bilangan bulat, Euclid adalah seorang matematikawan asal Yunani yang pertama kali menuliskan algoritma ini didalam bukunya yang terkenal yaitu Element.

Lemma 1: (Lemma Euclid)

Jika $a \mid b c$ dan $(a, b)=1$ maka $a \mid c$

\section{Bukti :}

Untuk $(a, b)=1$ berdasarkan definisi 3, terdapat bilangan bulat $x, y$ dimana

$$
(a \times x)+(b \times y)=1 .
$$

Karena $a \mid(b \times c)$, terdapat suatu bilangan bulat $s$ dimana $a \times s=b \times c$. Selanjutnya $c=c \times$ $1=c \times a \times x+c \times b \times y=c \times a \times x+c \times$ $s \times y$ yang berarti $a \mid c .^{[7]}$

\section{Definisi 6 : (Kelipatan Persekutuan Terkecil)}

Diberikan $\boldsymbol{a}, \boldsymbol{b} \in \mathbb{Z}$ yang keduanya tidak nol, bilangan bulat positif terkecil yang merupakan kelipatan dari a dan $b$ dinamakan kelipatan persekutuan terkecil (KPK) dari a dan $\boldsymbol{b}$, dan dinotasikan dengan $[\boldsymbol{a}, \boldsymbol{b}]$, atau dapat kita catat bahwa jika $\boldsymbol{a} \mid \boldsymbol{c}$ dan $\boldsymbol{b} \mid \boldsymbol{c}$ maka $[\boldsymbol{a}, \boldsymbol{b}] \mid \boldsymbol{c}$.

\section{Keterbagian}

\section{Definisi 7 : (definisi keterbagian)}

Bila $\boldsymbol{a}$ dan $\boldsymbol{b}$ suatu bilangan bulat positif, dan $\boldsymbol{a}=\boldsymbol{q} \times \boldsymbol{b}$ untuk semua bilangan bulat $\boldsymbol{q}$ maka dapat dikatakan bahwa $\boldsymbol{b}$ dapat membagi habis $\boldsymbol{a}$, atau $\boldsymbol{b}$ adalah faktor dari $\boldsymbol{a}$, dan dapat 
ditulis $\boldsymbol{a} \mid \boldsymbol{b}$, jika $\boldsymbol{a} \nmid \boldsymbol{b}$ maka $\boldsymbol{b}$ bukan faktor dari a.

\section{Teorema 1: (Algoritma pembagian)}

Untuk setiap pasangan bilangan bulat $\boldsymbol{a}$ dan $\boldsymbol{p}$ dimana $\boldsymbol{p}>\mathbf{0}$, selalu terdapat secara tunggal pasangan bilangan bulat $\boldsymbol{q}$ dan $\boldsymbol{r}$ yang memenuhi:

$$
\boldsymbol{a}=(\boldsymbol{p} \times \boldsymbol{q})+\boldsymbol{r} ; \mathbf{0} \leq \boldsymbol{r}<\boldsymbol{p}
$$

Dalam persamaan ini $\boldsymbol{q}$ dinamakan hasil bagi (quotient) dan $\boldsymbol{r}$ dinamakan sisa atau residu (remainder).

\section{Bukti:}

Untuk diketahui bahwa $\lfloor x\rfloor$ adalah fungsi floor yang menyatakan bilangan bulat terbesar yang lebih kecil atau sama dengan $x$ dimana $x$ adalah sembarang bilangan riil yang mempunyai sifat $x-1<\lfloor x\rfloor \leq x$. Sekarang diambil $p>0$ dan misalkan diambil sembarang bilangan bulat $a$ yang didefinisikan,

$$
q=\left\lfloor\frac{a}{p}\right\rfloor, r=a-p \times q
$$

Secara jelas pada $a=p \times q+r$, tetapi perlu membuktikan bahwa $0 \leq r<p$. Dan berdasarkan sifat fungsi floor,

$$
\frac{a}{p}-1<\left\lfloor\frac{a}{p}\right\rfloor \leq \frac{a}{p}
$$

Dengan mengalikan semua suku dengan $-p$

$$
p-a>-p\left\lfloor\frac{a}{p}\right\rfloor \geq-a
$$
diperoleh;

Sekarang tambahkan a kesemua ruas

$$
p>a-p q \geq 0
$$

Karena $r=a-p q$ maka,

$$
0 \leq r<p
$$

\section{Teorema 2:}

Untuk setiap pasangan bilangan bulat $a$ dan $p$ dimana $p<0$, selalu terdapat dengan tunggal pasangan bilangan bulat $q$ dan $r$ sehingga,

$$
a=q \times(-p)+r, 0 \leq r<-p
$$

Bukti :

Berdasarkan teorema 1, karena $q$ merupakan bilangan bulat, dengan mengambil $q=-q$ maka,

$$
\begin{aligned}
a & =(p \times(-q))+r, 0 \leq r<p \\
& =(q \times(-p))+r, 0 \leq r<-p
\end{aligned}
$$

Akan tetapi pada teorema 1 untuk setiap pasangan bilangan bulat $a$ dan $p$ dimana $p \neq 0$, selalu terdapat dengan tunggal pasangan bilangan bulat $q$ dan $r$ sehingga,

$$
a=q \times p+r, 0 \leq r<|q|
$$

Dengan membagi kedua ruas dengan $q$ dimana $q>0$ diperoleh :

$$
\frac{a}{q}=p+\frac{r}{q} \text {, dengan } 0 \leq \frac{r}{q}<-p
$$

Persamaan (2.3) menandakan bahwa dengan $p$ adalah hasil bagi dan $\frac{r}{q}$ menyatakan sisa yang selalu berada pada batas $0 \leq \frac{r}{q}<-p .^{[7]}$

\section{Kekongruenan}

Kekongruenan adalah sebuah kesamaan dalam rumus matematika yaitu ketika rumus itu ruas kiri sama dengan ruas kanan. Kekongruenan dalam teori bilangan membahas mengenai sisasisa dari suatu bilangan bulat yang tidak habis di bagi oleh bilangan lain, kekongruenan disimbolkan dengan " $\equiv "$,

\section{Definisi 8: (definisi kekongruenan)}

Misalkan $\boldsymbol{p} \epsilon \mathbb{N}$ dan $\boldsymbol{a}, \boldsymbol{b} \in \mathbb{Z}$. Dikatakan kongruen modulo $\boldsymbol{p}$, yang dinotasikan dengan $\boldsymbol{a} \equiv \boldsymbol{b}(\boldsymbol{m o d} \boldsymbol{p})$, jika $\boldsymbol{p}$ membagi habis $\boldsymbol{a}-\boldsymbol{b}$ atau $\boldsymbol{p} \mid(\boldsymbol{a}-\boldsymbol{b})$.

Contoh : $24 \equiv 3(\bmod 7)$,

24 modulo 7 akan bersisa 3, karena berdasarkan definisi 8,7 dapat membagi habis $(24-3)$ atau $7 \mid(24-3)$.

Bilangan bulat $a$ selalu terdapat hasil bagi dengan simbol $q$ dan jika tak membagi habis, maka ada sisa dengan simbol $r$ dan diperoleh kembali teorema 1, atau dapat ditulis

$$
a \equiv r(\bmod p)
$$

\section{Teorema 3 :(teorema-teorema kekongruenan)} Misalkan $p$ adalah bilangan bulat positif sembarang dan misalkan $a, b, c$, dan $d$ adalah bilangan bulat;

1. $a \equiv a(\bmod p)$

2. Jika $a \equiv b(\bmod p) \operatorname{maka} b \equiv a(\bmod p)$

3. Jika $a \equiv b(\bmod p)$ dan $b \equiv$ $c(\bmod p) \operatorname{maka} a \equiv c(\bmod p)$ 
4. Jika $a \equiv b(\bmod p) d a n$

$c \equiv d(\bmod p) \operatorname{maka}$ :

a. $a \pm c \equiv b \pm d(\bmod p)$

b. $a c \equiv b d(\bmod p)$

c. $a \pm c \equiv b \pm c(\bmod p)$

d. $a c \equiv b c(\bmod p)$

\section{Notasi Sigma}

Jumlahan dari beberapa barisan bilangan baik positif maupun negatif disebut deret, untuk penggunaan notasi sigma yang disimbolkan dengan " $\sum$ ", (baca: sigma). Untuk diketahui jika;

$$
\sum_{i=0}^{n} i=0+1+2+3+\cdots+n
$$

Yang menyatakan jumlahan satu bilangan yang dimulai dari $i=0$ sampai $i=n$, dengan 0 menyatakan batas awal dan $n$ menyatakan batas terakhir dari penjumlahan bilangan itu, dalam penulisan lainnya,

$1+2 p+3 p^{2}+4 p^{3}+\cdots=\sum_{k=1}^{\infty} k \cdot p^{k-1}$

\section{Permutasi dan Kombinasi}

merupakan bentuk khusus aplikasi aturan perkalian. Misalkan jumlah objek adalah $n$, maka urutan pertama dipilih dari $n$ objek, urutan kedua dipili dari $n-1$ objekn urutan ketiga dipilih dari $n-3$ objek, begitu seterusnya sampai urutan terakhir dipilih 1 objek yang tersisa, menurut kaidah permutasi dari $n$ objek adalah;

$$
n(n-1)(n-2) \ldots(2)(1)=n \text { ! }
$$

\section{Definisi 10 :(definisi permutasi) :}

Permutasi $r$ dari $n$ objek adalah jumlah kemungkinan urutan $r$ buah objek yang dipilih dari $n$ buah objek, dengan $r \leq n$, yang dalam hal ini, pada setiap kemungkinan urutan tidak ada objek yang sama. Jadi, jumlah susunan berbeda dari pemilihan $r$ objek yang diambil dari $n$ objek disebut permutasi-r, dilambangkan dengan $p(n, r) .^{[6]}$

$$
p(n, r)=\frac{n !}{(n-r) !}
$$

\section{Definisi 11 : (definisi kombinasi)}

Kombinasi $r$ elemen dari $n$ elemen adalah jumlah pemilihan yang tidak terurut $r$ elemenyang diambil dari $n$ buah elemen. ${ }^{[6]}$

Rumus $\frac{n !}{r !(n-r) !}$ disebut rumus kombinasi-r, dan dilambanngkan dengan $C(n, r)$ atau $\left(\begin{array}{l}n \\ r\end{array}\right)$, jadi;

$$
\begin{aligned}
C(n, r) & =\left(\begin{array}{l}
n \\
r
\end{array}\right) \\
& =\frac{n !}{r !(n-r) !}
\end{aligned}
$$

\section{Induksi Matematika Kuat}

Induksi matematika kuat yang berbunyi : Misalkan $p(n)$ adalah pernyataan perihal bilangan bulat dan ingin membuktikan bahwa $p(n)$ benar untuk semua bilangan bulat $n \geq n_{0}$. Untuk membuktikan ini, hanya perlu menunjukan bahwa;

1. $p\left(n_{0}\right)$ benar, dan

2. Jika $p\left(n_{0}\right), p\left(n_{0}+1\right), p\left(n_{0}+2\right), \ldots, p(n)$ benar, maka $p(n+1)$ juga benar untuk setiap bilangan bulat $n \geq n_{0}$, sehingga $p(n)$ benar untuk semua bilangan bulat $n \geq n_{0} \cdot{ }^{[6]}$

\section{Identitas Pascal}

Secara formal identitas pascal dapat dinyatakan dalam persamaan-persamaan :

$$
\begin{aligned}
& \text { 1. }\left(\begin{array}{c}
n+1 \\
k
\end{array}\right)=\left(\begin{array}{c}
n \\
k-1
\end{array}\right)+\left(\begin{array}{l}
n \\
k
\end{array}\right) \\
& \text { 2. }\left(\begin{array}{l}
n \\
k
\end{array}\right)=\left(\begin{array}{c}
n \\
n-k
\end{array}\right) \\
& \text { 3. }\left(\begin{array}{c}
k \\
k
\end{array}\right)+\left(\begin{array}{c}
k+1 \\
k
\end{array}\right)+\left(\begin{array}{c}
k+2 \\
k
\end{array}\right)+ \\
& \left(\begin{array}{c}
k+4 \\
k
\end{array}\right) \ldots+\left(\begin{array}{l}
n \\
k
\end{array}\right)=\left(\begin{array}{l}
n+1 \\
k+1
\end{array}\right)
\end{aligned}
$$

\section{Teorema Fermat}

Teorema Fermat merupakan suatu teori yang sangat terkenal dalam teori bilangan, teorema ini dibuktikan oleh seorang matematikawan dari negara Prancis yang bernama Piere de Fermat. ${ }^{[11]}$

\section{Teorema 3: (Teorema Kecil Fermat)}

Jika $p$ suatu bilangan prima dan $(a, p)=1$ untuk suatu bilangan bulat $a$ maka : 


$$
a^{p-1} \equiv 1(\bmod p)
$$

Atau dengan kata lainnya "jika $\mathrm{p}$ adalah bilangan prima dan a adalah prima relatif dengan p maka $a^{p-1}-1$ dapat dibagi oleh $p$ ", karena ada suatu bilangan $q$, penulisan lain untuk teorema Fermat ini adalah;

$$
q_{p}(a)=\frac{a^{p-1}-1}{p}
$$

\section{Teorema Binomial}

Teorema Binomial adalah rumus penjabaran $(x+y)^{n}$, dengan $n$ bilangan bulat tak negative. Rumus ini digunakan untuk mencari jika pangkat yang tinggi seperti $(x+y)^{20},(x+y)^{50},(x+y)^{100}$ dan sebagai nya, Dengan adanya teorema binomial inilah cara mudah dan cepat dapat dipakai untuk menjabarkan suatu bilangan dengan pangkat tertinggi.

\section{Teorema 4 : (Teorema Binomial)}

Misalkan $x$ dan $y$ adalah bilanganbilangan riil dan $n$ adalah bilangan bulat tak negatif, maka;

$$
(x+y)^{n}=\sum_{k=0}^{n}\left(\begin{array}{l}
n \\
k
\end{array}\right) x^{n-k} y^{k}
$$

Berdasarkan identitas pascal dan teorema binomial, diperoleh identitas berikut,

$$
\sum_{k=0}^{n} \frac{(1-x)^{k}}{k}=\sum_{k=0}^{n}\left(\begin{array}{l}
n \\
k
\end{array}\right) \frac{(-1)^{k}}{k}\left(x^{k}-1\right)
$$

\section{Bilangan Bernoulli}

\section{Definisi 12: (definisi bilangan Bernoulli)}

Dengan $B_{n}$ menyatakan bilangan bernoulli, $B_{n}(x)$ menyatakan suku banyak bilangan bernoulli dan nilai $B_{2 n+1}=$ 0 untuk $n=1,2,3,4, \ldots$, maka,

$$
\begin{aligned}
& B_{0}=1, \sum_{\substack{k=0 \\
\text { Untuk }}}^{n-1}\left(\begin{array}{l}
n \\
k
\end{array}\right) B_{k}=2,3,4,5, \ldots \\
& B_{n}(x)=\sum_{\substack{k=0 \\
\text { Untuk } n \\
[2]}}^{n}\left(\begin{array}{l}
n \\
k
\end{array}\right) B_{k} x^{n-k}=0,3,4,5, \ldots
\end{aligned}
$$

Dengan kekongruenan bahwa untuk suatu $p$ bilangan prima ganjil dan $k$ suatu bilangan bulat positif dengan $(p-1) \nmid k$, maka berlaku,

$$
\begin{aligned}
& 1^{k}+2^{k}+3^{k}+\cdots+(p-1)^{k} \\
& =\sum_{j=1}^{p-1} j^{k} \equiv p B_{k}\left(\bmod p^{2}\right)^{[3]}
\end{aligned}
$$

Dan untuk beberapa bilangan prima $p>$ 3, berlaku pula

$$
\begin{aligned}
& \sum_{\substack{k=1 \\
p-1}}^{\frac{p-1}{2}} \frac{1}{k^{3}} \equiv-2 B_{p-3}(\bmod p) \\
& \sum_{\substack{k=1 \\
\frac{p-1}{2}}}^{\frac{1}{k^{2}}} \equiv \frac{2}{3} p B_{p-3}\left(\bmod p^{2}\right) \\
& \sum_{\substack{k=1 \\
p-1}}^{\frac{1}{k^{2}}} \equiv \frac{7}{3} p B_{p-3}\left(\bmod p^{2}\right) \\
& \sum_{k=1}^{1} \frac{1}{k} \equiv-\frac{1}{3} p^{2} B_{p-3}\left(\bmod p^{3}\right)
\end{aligned}
$$

Secara umum, diberikan suatu bilangan prima $p>5$ maka, ${ }^{[10]}$

$$
\sum_{x=1}^{\frac{p-1}{2}} \frac{1}{x^{k}} \equiv\left\{\begin{array}{l}
\frac{k\left(2^{k+1}-1\right)}{2(k+1)} p B_{p-1-k}\left(\bmod p^{2}\right)(*) \\
-\frac{2^{k}-2}{k} B_{p-k}(\bmod p)
\end{array}\right.
$$

(*) Jika $k \in\{2,4,6, \ldots, p-5\}$

(**) Jika $k \in\{3,5, \ldots, p-4\}$

\section{Bilangan Harmonik}

Bilangan Harmonik adalah bilangan yang didefinisikan untuk penjumlahan serangkain harmonik, dimana untuk $n \geq 1, m \geq 1$ maka,

$$
\begin{aligned}
& H_{n}=\frac{1}{1}+\frac{1}{2}+\frac{1}{3}+\frac{1}{4}+\cdots+\frac{1}{n} \\
& H_{n, m}=\frac{1}{1^{m}}+\frac{1}{2^{m}}+\frac{1}{3^{m}}+\frac{1}{4^{m}}+\cdots+\frac{1}{n^{m}}
\end{aligned}
$$

\section{Definisi 13 : (Bilangan Harmonik)}

Untuk penjumlahan serangkaian bilangan sesara harmonik, diberikan $n \geq 1, m \geq 1$,

$$
H_{0}=0, H_{0,0}=0, H_{n}=\sum_{k=1}^{n} \frac{1}{k} \text {, dan }
$$




$$
H_{n, m}=\sum_{k=1}^{n} \frac{1}{k^{m}}
$$

Bilangan Harmonik memenuhi dengan dentitas seperti;

$$
\begin{aligned}
& \text { a. } H_{n}=H_{n-1}+\frac{1}{n} \\
& \text { b. } H_{n}=H_{n+1}-\frac{1}{n+1} \\
& \text { c. } \sum_{k=1}^{n-1} H_{k}=n H_{n}-n \\
& \text { d. } \sum_{k=n-1}^{n-1}\left(\begin{array}{c}
k \\
n-1
\end{array}\right) H_{k}=\left(\begin{array}{l}
n-1 \\
n-1
\end{array}\right) H_{n-1}
\end{aligned}
$$

\section{Lemma 1: (lemma kekongruenan bilangan harmonik)}

Diberikan $p$ sebuah bilangan prima ganjil dan $k \in\{0,1,2, \ldots, p-1\}$ dimana,

$$
\begin{aligned}
& \left(\begin{array}{c}
p-1 \\
k
\end{array}\right)(-1)^{k} \\
\equiv & \left(1-p H_{k}+\frac{p^{2}}{2}\left(\left(H_{k}\right)^{2}-H_{k, 2}\right)\right. \\
& -\frac{p^{3}}{6}\left(\left(H_{k}\right)^{3}-3\left(H_{k}\right)\left(H_{k, 2}\right)+2\right. \\
& \left(\bmod p^{4}\right) \\
\equiv & \left(1-p H_{k}+p^{2} \frac{1}{2}\left(\left(H_{k}\right)^{2}-H_{k, 2}\right)\right) \\
& \left(\bmod p^{3}\right) \quad\left(\bmod p^{2}\right)
\end{aligned}
$$$$
\left.-\frac{p^{3}}{6}\left(\left(H_{k}\right)^{3}-3\left(H_{k}\right)\left(H_{k, 2}\right)+2 H_{k, 3}\right)\right)
$$

Lemma 2: (lemma kekongruenan bilangan harmonik) maka

Untuk beberapa bilangan prima $p>3$,

$$
H_{p-1} \equiv 0\left(\bmod p^{2}\right)
$$

Secara umum untuk suatu bilangan prima $p>3$ dan $k \in\{1,2,3, \ldots, p-4\}$ maka diperoleh,

$$
\sum_{x=1}^{p-1} \frac{1}{x^{k}}=H_{p-1, k} \equiv 0(\bmod p) .^{[12]}
$$

\section{METODOLOGI}

Artikel ini, mengkaji berbagai buku atau beberapa jurnal yang berkaitan, yang ditulis oleh para pakar matematika. Langkah-langkah yang ditempuh dalam mengkaji kekongruenan untuk hasil bagi fermat modulo ini adalah sebagai berikut:

1. Menemukan beberapa persamaan pada kombinatorik, dan bilangan harmonik.

2. Menemukan beberapa kekongruenan untuk modulo $p, p^{2}, p^{3}$ dan $p^{4}$

3. Membuktikan kekongruenan hubungan antara bilangan Bernoulli dan bilangan harmonik modulo $p^{4}$ untuk $p$ suatu bilangan prima ganjil positif.

\section{PEMBAHASAN}

1. Menemukan beberapa persamaan pada kombinatorik, dan bilangan harmonik.

$$
\left(\begin{array}{l}
p \\
k
\end{array}\right)=\frac{p}{k}\left(\begin{array}{l}
p-1 \\
k-1
\end{array}\right)
$$

Diberikan $p>k$ dengan $p$ suatu bilangan prima ganjil, dan $k$ suatu bilangan asli, maka diperoleh persamaan-persamaan harmonik,

$$
\begin{aligned}
& \text { a. } H_{p-(k+1)}=H_{p-1}-\sum_{j=1}^{k} \frac{1}{p-j} \\
& \text { b. }\left(H_{p-(k+1)}\right)^{2}=\left(H_{p-1}\right)^{2}- \\
& \quad 2 H_{p-1} \sum_{j=1}^{k} \frac{1}{p-j}+\left(\sum_{j=1}^{k} \frac{1}{p-j}\right)^{2} \\
& \text { c. } H_{p-(k+1), 2}=H_{p-1,2} \\
& -\sum_{j=1}^{k} \frac{1}{(p-j)^{2}}
\end{aligned}
$$

Untuk persamaan-persamaan bilangan harmonik lainnya diperoleh,

$$
\begin{aligned}
& \sum_{\substack{k=1 \\
k \text { ganjil }}}^{p-1} \frac{H_{k}}{k^{2}}=\sum_{\substack{k=1 \\
k \text { ganjil }}}^{p-1} \frac{H_{k-1}}{k^{2}}+\sum_{\substack{k=1 \\
k \text { ganjil }}}^{p-1} \frac{1}{k^{3}} \\
& \sum_{k=1}^{p-1} \frac{H_{k}^{2}}{k^{2}}=\sum_{k=1}^{p-1} \frac{H_{k-1}^{2}}{k^{2}}+\sum_{k=1}^{p-1} \frac{2 H_{k-1}}{k^{3}}+\sum_{k=1}^{p-1} \frac{1}{k^{4}} \\
& \sum_{k=1}^{p-1} \frac{H_{k, 2}}{k^{2}}=\sum_{k=1}^{p-1} \frac{H_{k-1,2}}{k^{2}}+\sum_{k=1}^{p-1} \frac{1}{k^{4}}
\end{aligned}
$$




$$
\begin{aligned}
& \sum_{\substack{k=2 \\
k \text { genap }}}^{p-1} \frac{H_{k-1}}{k^{2}}=\sum_{k=1}^{p-1} \frac{H_{k-1}}{k^{2}}-\sum_{\substack{k=1 \\
k \text { ganjil }}}^{p-1} \frac{H_{k-1}}{k^{2}} \\
& \sum_{\substack{k=2 \\
k \text { genap }}}^{p-1} \frac{H_{k-1}^{2}}{k^{2}}=\sum_{k=1}^{p-1} \frac{H_{k-1}^{2}}{k^{2}}-\sum_{\substack{k=1 \\
k \text { ganjil }}}^{p-1} \frac{H_{k-1}^{2}}{k^{2}} \\
& \sum_{\substack{k=2 \\
k \text { genap }}}^{p-1} \frac{H_{k-1,2}}{k^{2}}=\sum_{k=1}^{p-1} \frac{H_{k-1,2}}{k^{2}}-\sum_{\substack{k=1 \\
k \text { ganjil }}}^{p-1} \frac{H_{k-1,2}}{k^{2}} \\
& \sum_{\substack{k=2 \\
k \text { genap }}}^{p-1} \frac{H_{k-1}}{k^{3}}=\sum_{k=1}^{p-1} \frac{H_{k-1}}{k^{3}}-\sum_{\substack{k=1 \\
k \text { ganjil }}}^{p-1} \frac{H_{k-1}}{k^{3}} \\
& \sum_{\substack{k=2 \\
k \text { genap }}}^{p-1} \frac{H_{k-1}}{k^{3}}=\sum_{\substack{k=1 \\
k \text { ganjil }}}^{p-1} \frac{H_{(p-k)-1}}{(p-k)^{3}} \\
& \sum_{\substack{k=2 \\
k \text { genap }}}^{p-1} \frac{H_{k-1}^{2}}{k^{2}}=\sum_{\substack{k=1 \\
k \text { ganjil }}}^{p-1} \frac{H_{(p-k)-1}^{2}}{(p-k)^{2}} \\
& \sum_{\substack{k=2 \\
k \text { genap }}}^{p-1} \frac{H_{k-1,2}}{k^{2}}=\sum_{\substack{k=1 \\
k \text { ganjil }}}^{p-1} \frac{H_{(p-k)-1,2}}{(p-k)^{2}}
\end{aligned}
$$

2. Menemukan beberapa kekongruenan untuk modulo $p, p^{2}, p^{3}$ dan $p^{4}$.

Dari identitas persamaan (2.13), dengan mengambil $x=0$ dan $n=p$ maka diperoleh,

$$
\begin{aligned}
& \sum_{k=1}^{p} \frac{1}{k}=\sum_{k=1}^{p}\left(\begin{array}{l}
p \\
k
\end{array}\right)(-1)^{k}\left(-\frac{1}{k}\right) \\
& \sum_{k=1}^{p-1} \frac{1}{k}+\frac{1}{p}=\sum_{k=1}^{p-1}\left(\begin{array}{l}
p \\
k
\end{array}\right)(-1)^{k}\left(-\frac{1}{k}\right) \\
& \quad+\left(\begin{array}{l}
p \\
p
\end{array}\right)(-1)^{p}\left(-\frac{1}{p}\right) \\
& \sum_{k=1}^{p-1} \frac{1}{k}=-\sum_{k=1}^{p-1}\left(\begin{array}{l}
p \\
k
\end{array}\right)\left(\frac{(-1)^{k}}{k}\right)+\left(\frac{-(-1)^{p}}{p}\right)-\frac{1}{p}
\end{aligned}
$$

$$
\sum_{k=1}^{p-1} \frac{1}{k}=-\sum_{k=1}^{p-1}\left(\begin{array}{l}
p \\
k
\end{array}\right) \frac{(-1)^{k}}{k}-\left(\frac{(-1)^{p}+1}{p}\right)
$$

Dari persamaan (4.4) untuk $p$ suatu bilangan prima ganil positif diperoleh,

$$
\sum_{k=1}^{p-1} \frac{1}{k}=-\sum_{k=1}^{p-1}\left(\begin{array}{l}
p \\
k
\end{array}\right) \frac{(-1)^{k}}{k}
$$

Dengan mensubtitusikan persamaan (4.1) ke persamaan (4.5) diperoleh,

$$
\sum_{k=1}^{p-1} \frac{1}{k}=-p \sum_{k=1}^{p-1}\left(\begin{array}{l}
p-1 \\
k-1
\end{array}\right) \frac{(-1)^{k}}{k^{2}}
$$

Dari lemma 1 (persamaan (2.18)) pada baris kedua, dengan mengganti $k=k-1$ diperoleh,

$$
\begin{aligned}
& \left(\begin{array}{l}
p-1 \\
k-1
\end{array}\right)(-1)^{k} \\
& \equiv-\left(1-p H_{k-1}+\frac{p^{2}}{2}\left(\left(H_{k-1}\right)^{2}-H_{k-1,2}\right)\right) \\
& \quad\left(\bmod p^{3}\right)
\end{aligned}
$$

Dengan mensubtitusikan persamaan (4.7) ke persamaan (4.6) diperoleh,

$$
\begin{gathered}
\sum_{k=1}^{p-1} \frac{1}{k} \equiv p \sum_{k=1}^{p-1} \frac{1}{k^{2}}\left(1-p H_{k-1}+p^{2} \frac{1}{2}\left(\left(H_{k-1}\right)^{2}-H_{k-1,2}\right)\right) \\
\left(\bmod p^{3}\right)
\end{gathered}
$$

$$
\sum_{k=1}^{p-1} \frac{1}{k} \equiv\left(p \sum_{k=1}^{p-1} \frac{1}{k^{2}}-p^{2} \sum_{k=1}^{p-1} \frac{H_{k-1}}{k^{2}}\right)
$$$$
\left(\bmod p^{3}\right)
$$

(2.15.2) dan (2.15.4) ke persamaan (4.8)diperoleh,

$$
\begin{aligned}
-\frac{1}{3} p^{2} B_{p-3} \equiv & \left(\frac{2}{3} p^{2} B_{p-3}-p^{2} \sum_{k=1}^{p-1} \frac{H_{k-1}}{k^{2}}\right) \\
& \left(\bmod p^{3}\right)
\end{aligned}
$$

Dengan sedikit proses aljabar diperoleh,

$$
\sum_{k=1}^{p-1} \frac{H_{k-1}}{k^{2}} \equiv B_{p-3}(\bmod p)
$$


Dari lemma 1 (persamaan (2.18)) pada baris pertama untuk $k=k-1$ diperoleh,

$$
\begin{aligned}
&\left(\begin{array}{l}
p-1 \\
k-1
\end{array}\right)(-1)^{k} \\
& \equiv-\left(1-p H_{k-1}+\frac{p^{2}}{2}\left(H_{k-1}^{2}-H_{k-1,2}\right)-\right. \\
&\left.\frac{p^{3}}{6}\left(H_{k-1}^{3}-3 H_{k-1} H_{k-1,2}+2 H_{k-1,3}\right)\right) \\
&\left(\bmod p^{4}\right)
\end{aligned}
$$

Dengan mensubtitusikan persamaan (4.10) ke persamaan (4.6) diperoleh,

$$
\begin{gathered}
\sum_{k=1}^{p-1} \frac{1}{k} \equiv p \sum_{k=1}^{p-1} \frac{1}{k^{2}}\left(1-p H_{k-1}+\frac{p^{2}}{2}\left(H_{k-1}^{2}-H_{k-1,2}\right)\right. \\
\left.-\frac{p^{3}}{6}\left(H_{k-1}^{3}-3 H_{k-1} H_{k-1,2}+2 H_{k-1,3}\right)\right) \\
\sum_{k=1}^{p-1} \frac{1}{k}=p^{4} q+p \sum_{k=1}^{p-1} \frac{1}{k^{2}}-p^{2} \sum_{k=1}^{p-1} \frac{H_{k-1}}{k^{2}} \\
+p^{3} \sum_{k=1}^{p-1} \frac{\left(H_{k-1}^{2}-H_{k-1,2}\right)}{2 k^{2}} \\
\sum_{k=1}^{p-1} \frac{\left(H_{k-1}^{3}-3 H_{k-1} H_{k-1,2}+2 H_{k-1,3}\right)}{6 k^{2}} \\
\sum_{k=1}^{p-1} \frac{1}{k} \equiv p \sum_{k=1}^{p-1} \frac{1}{k^{2}}-p^{2} \sum_{k=1}^{p-1} \frac{H_{k-1}}{k^{2}}+ \\
p^{3} \sum_{k=1}^{p-1} \frac{H_{k-1}^{2}}{2 k^{2}}-p^{3} \sum_{k=1}^{p-1} \frac{H_{k-1,2}}{2 k^{2}} \\
\left(\bmod p^{4}\right)
\end{gathered}
$$

Dengan mensubtitusikan persamaan (2.15.2), (2.15.4), dan (4.9) ke persamaan (4.11) diperoleh,

$$
\begin{aligned}
-\frac{1}{3} p^{2} B_{p-3} \equiv & \frac{2}{3} p^{2} B_{p-3}-p^{2} B_{p-3}+ \\
& p^{3} \sum_{k=1}^{p-1} \frac{H_{k-1}^{2}}{2 k^{2}}-p^{3} \sum_{k=1}^{p-1} \frac{H_{k-1,2}}{2 k^{2}} \\
& \left(\bmod p^{4}\right)
\end{aligned}
$$

$$
\sum_{k=1}^{p-1} \frac{H_{k-1}^{2}}{k^{2}} \equiv \sum_{k=1}^{p-1} \frac{H_{k-1,2}}{k^{2}}(\bmod p)
$$

Dari persamaan (4.2.1) dan berdasarkan lemma 2 (persamaan (2.19)) dapat ditulis,

$$
\begin{aligned}
H_{p-(k+1)} & =H_{p-1}-\sum_{j=1}^{k} \frac{1}{p-j} \\
& \equiv \sum_{j=1}^{k} \frac{1}{j}(\bmod p) \\
& \equiv H_{k}(\bmod p)
\end{aligned}
$$

Dari persamaan (4.13), maka persamaan (4.3.8) dapat ditulis,

$$
\begin{aligned}
\sum_{\substack{k=2 \\
k \text { genap }}}^{p-1} \frac{H_{k-1}}{k^{2}} & =\sum_{\substack{k=1 \\
k \text { ganjil } \\
p-1}}^{p-1} \frac{H_{(p-k)-1}}{(p-k)^{2}} \\
& \equiv \sum_{\substack{k=1 \\
k \text { ganjil }}} \frac{H_{k}}{k^{2}}(\bmod p)
\end{aligned}
$$

Untuk ruas paling kiri berdasarkan persamaan (4.3.4), dan ruas paling kanan berdasarkan persamaan (4.3.1), sehingga persamaan (4.14) dapat ditulis,

$$
\begin{gathered}
\sum_{k=1}^{p-1} \frac{H_{k-1}}{k^{2}} \equiv 2 \sum_{\substack{k=1 \\
k \text { ganjil } \\
p-1}}^{p-1} \frac{H_{k-1}}{k^{2}}+ \\
\sum_{\substack{k=1 \\
k \text { ganjil }}} \frac{1}{k^{3}}(\bmod p)
\end{gathered}
$$

kedua,

Persamaan (4.15) ruas kanan suku

$$
\begin{aligned}
\sum_{\substack{k=1 \\
k \text { ganjil }}}^{p-1} \frac{1}{k^{3}} & \equiv-\sum_{\substack{k=2 \\
k \text { genap } \\
\text { p-1 }}}^{p-1} \frac{1}{k^{3}}(\bmod p) \\
& \equiv-\frac{1}{8} \sum_{k=1}^{\frac{1}{k^{3}}} \frac{1}{\bmod p)}
\end{aligned}
$$

Dengan mnsubtitusikan persamaan (2.15.1), ke persamaan (4.16) diperoleh, 


$$
\sum_{\substack{k=1 \\ k \text { ganjil }}}^{p-1} \frac{1}{k^{3}} \equiv \frac{1}{4} B_{p-3}(\bmod p)
$$

Pada persamaan (4.15) untuk ruas kiri subtitusikan persamaan (4.9), dan ruas kanan suku kedua subtitusikan persamaan (4.17) maka diperoleh,

$$
\frac{3}{8} B_{p-3} \equiv \sum_{\substack{k=1 \\ k \text { ganjil }}}^{p-1} \frac{H_{k-1}}{k^{2}}(\bmod p)
$$

Berdasarkan teorema 3 nomor 2, persamaan (4.18) dapat ditulis,

$$
\sum_{\substack{k=1 \\ k \text { ganjil }}}^{p-1} \frac{H_{k-1}}{k^{2}} \equiv \frac{3}{8} B_{p-3}(\bmod p)
$$

Dari persamaan (4.2.2) dan berdasarkan lemma 2 (persamaan (2.18)) maka diperoleh,

$$
\begin{aligned}
H_{(p-k)-1}^{2} & \equiv\left(\sum_{j=1}^{k} \frac{1}{j}\right)^{2}(\bmod p) \\
& \equiv H_{k}^{2}(\bmod p)
\end{aligned}
$$

Berdasarkan persamaan persamaan (4.3.9) dapat ditulis,

$$
\sum_{\substack{k=2 \\ k \text { genap }}}^{p-1} \frac{H_{k-1}^{2}}{k^{2}} \equiv \sum_{\substack{k=1 \\ k \text { ganjil }}}^{p-1} \frac{H_{k}^{2}}{k^{2}}(\bmod p)
$$

Persamaan (4.21) ruas kiri subtitusikan persamaan (4.3.5), dan ruas kanan subtitusikan persamaan (4.3.2) ( $k$ ganjil), maka dapat di tulis menjadi,

$$
\begin{aligned}
\sum_{k=1}^{p-1} \frac{H_{k-1}^{2}}{k^{2}} \equiv & 2 \sum_{\substack{k=1 \\
k \text { ganjil } \\
p-1}}^{p-1} \frac{H_{k-1}^{2}}{k^{2}}+2 \sum_{\substack{k=1 \\
k \text { ganjil }}}^{p-1} \frac{H_{k-1}}{k^{3}} \\
& +\sum_{\substack{k=1 \\
k \text { ganjil } \\
p-1}} \frac{1}{k^{4}}(\bmod p) \\
\sum_{\substack{k=1 \\
k \text { ganjil }}}^{p-1} \frac{1}{k^{4}} \equiv & -\sum_{\substack{k=2 \\
k \text { genap }}} \frac{1}{k^{4}}(\bmod p)
\end{aligned}
$$

$$
\equiv-\frac{1}{16} \sum_{k=1}^{\frac{p-1}{2}} \frac{1}{k^{4}}(\bmod p)
$$

Pada persamaan (2.16) untuk $k$ yang genap dan pada persamaan tersebut, dengan $x$ diganti dengan $k$ maka diperoleh,

$$
\begin{aligned}
\sum_{k=1}^{\frac{p-1}{2}} \frac{1}{k^{4}} & \equiv \frac{4\left(2^{4+1}-1\right)}{2(4+1)} p B_{p-1-4}\left(\bmod p^{2}\right) \\
\sum_{k=1}^{\frac{p-1}{2}} \frac{1}{k^{4}} & \equiv 0(\bmod p)
\end{aligned}
$$

Dengan mensubtitusikan persamaan (4.24) ke persamaan (4.23) diperoleh,

$$
\sum_{\substack{k=1 \\ k \text { ganjil }}}^{p-1} \frac{1}{k^{4}} \equiv 0(\bmod p)
$$

Untuk ruas kanan suku kedua, persamaan (4.3.7) dapat diubah menjadi,

$$
\sum_{\substack{k=1 \\ k \text { ganjil }}}^{p-1} \frac{H_{k-1}}{k^{3}} \equiv-\sum_{\substack{k=2 \\ k \text { genap }}}^{p-1} \frac{H_{k-1}}{k^{3}}(\bmod p)
$$

Subtitusikan persamaan

kepersamaan (4.26) diperoleh,

$$
\begin{aligned}
& \sum_{\substack{k=1 \\
k \text { ganjil }}}^{p-1} \frac{H_{k-1}}{k^{3}} \equiv-\sum_{\substack{k=1 \\
k \text { ganjil }}}^{p-1} \frac{H_{p-(k+1)}}{(p-k)^{3}}(\bmod p) \\
& \equiv-\left(\sum_{\substack{k=1 \\
k \text { ganjil } \\
(\bmod p)}}^{p-1} \frac{H_{k-1}}{k^{3}}+\sum_{\substack{k=1 \\
k \text { ganjil }}}^{p-1} \frac{1}{k^{4}}\right)
\end{aligned}
$$

Menurut relasi kekongruenan, persamaan (4.27) dapat ditulis,

$$
\begin{aligned}
& 2 \sum_{\substack{k=1 \\
k \text { ganjil } \\
p-1}}^{p-1} \frac{H_{k-1}}{k^{3}} \\
& \equiv \sum_{\substack{k=1 \\
k \text { ganjil }}} \frac{1}{k^{4}}(\bmod p)
\end{aligned}
$$

Subtitusikan persamaan (4.25) ke persamaan (4.28) diperoleh, 


$$
2 \sum_{\substack{k=1 \\ k \text { ganjil }}}^{p-1} \frac{H_{k-1}}{k^{3}} \equiv 0 \quad(\bmod p)
$$

Dengan mensubtitusikan persamaan (4.25) dan (4.29) ke persamaan (4.22) diperoleh,

$$
\sum_{\substack{k=1 \\ k \text { ganjil }}}^{p-1} \frac{H_{k-1}^{2}}{k^{2}} \equiv \sum_{k=1}^{p-1} \frac{H_{k-1}^{2}}{2 k^{2}}(\bmod p)
$$

Dari persamaan (4.2.3) mensubtitusikan persamaan $(k=2)$ diperoleh,

$$
H_{p-(k+1), 2}=0-\sum_{k=1}^{p-1} \frac{1}{(p-k)^{2}} \equiv H_{k, 2}(\bmod p)
$$

Menurut persamaan (4.31), persamaan (4.3.10) dapat ditulis menjadi,

$$
\sum_{\substack{k=2 \\ k \text { genap }}}^{p-1} \frac{H_{k-1,2}}{k^{2}} \equiv \sum_{\substack{k=1 \\ k \text { ganjil }}}^{p-1} \frac{H_{k, 2}}{k^{2}}(\bmod p)
$$

Dari persamaan (4.32), ruas kiri subtitusikan persamaan (4.3.6) dan ruas kanan subtitusikan persamaan (4.3.3), maka dapat ditulis menjadi,

$$
\begin{aligned}
& \sum_{k-1}^{p-1} \frac{H_{k-1,2}}{k^{2}} \equiv 2 \sum_{\substack{k=1 \\
k \text { ganjil } \\
p-1}}^{p-1} \frac{H_{k-1,2}}{k^{2}}+ \\
& \sum_{\substack{k=1 \\
k \text { ganjil }}} \frac{1}{k^{4}}(\bmod p)
\end{aligned}
$$

Persamaan (4.33) ruas kanan suku kedua, subtitusikan persamaan (4.25), dan menurut teorema 3 nomor 3 maka diperoleh

$$
\sum_{\substack{k=1 \\ k \text { ganjil }}}^{p-1} \frac{H_{k-1,2}}{k^{2}} \equiv \sum_{k-1}^{p-1} \frac{H_{k-1,2}}{2 k^{2}}(\bmod p)
$$

3. Membuktikan kekongruenan antara bilangan Bernoulli dan bilangan harmonik modulo $p^{4}$ untuk $p$ suatu bilangan prima ganjil positif.

Menurut persamaan (2.15), dengan mengganti $x=-1$ dan $n=p$ diperoleh,

$$
\begin{aligned}
\sum_{k=1}^{p} \frac{2^{k}}{k}= & \sum_{k=1}^{p}\left(\begin{array}{l}
p \\
k
\end{array}\right)(-1)^{k} \frac{(-1)^{k}-1}{k} \\
\sum_{k=1}^{p-1} \frac{2^{k}}{k} & =\sum_{k=1}^{p-1}\left(\begin{array}{l}
p \\
k
\end{array}\right)(-1)^{k} \frac{(-1)^{k}-1}{k} \\
& +\left(\frac{1-(-1)^{p}-2^{p}}{p}\right)
\end{aligned}
$$

Untuk $p$ suatu bilangan prima ganjil positif $(-1)^{p}=-1$, dan ruas kanan suku kedua subtitusikan persamaan (4.1) sehingga dapat ditulis menjadi,

$$
\begin{gathered}
\sum_{k=1}^{p-1} \frac{2^{k}}{k}=\sum_{k=1}^{p-1} p\left(\begin{array}{l}
p-1 \\
k-1
\end{array}\right)(-1)^{k} \frac{(-1)^{k}-1}{k^{2}} \\
+\frac{2-2^{p}}{p} \\
\sum_{k=1}^{p-1} \frac{2^{k}}{k}+2\left(\frac{2^{p-1}-1}{p}\right)=\sum_{k=1}^{p-1} p\left(\begin{array}{l}
p-1 \\
k-1
\end{array}\right) \\
(-1)^{k} \frac{(-1)^{k}-1}{k^{2}}
\end{gathered}
$$

Berdasarkan lemma 1 (persamaan (2.18)) baris pertama, dengan mengganti $k=k-1$ diperoleh,

$$
\begin{aligned}
- & \left(\begin{array}{l}
p-1 \\
k-1
\end{array}\right)(-1)^{k} \\
\equiv & 1-p H_{k-1}+p^{2}\left(\frac{\left(H_{k-1}\right)^{2}-H_{k-1,2}}{2}\right) \\
& -p^{3} \frac{\left(\left(H_{k-1}\right)^{3}-3 H_{k-1} H_{k-1.2}\right)}{6} \\
& -p^{3}\left(\frac{2 H_{k-1,3}}{6}\right)\left(\bmod p^{4}\right)
\end{aligned}
$$

Berdasarkan teorema Fermat pada persamaan (2.11), $\left(q_{p}(a)=\frac{a^{p-1}}{p}\right)$ dengan $a=$ 2, dan mensubtitusikan persamaan (4.37) kepersamaan (4.36) serta untuk suatu bilangan asli positif $k$ ganjil, $(-1)^{k}=-1$ sehinggan dapa ditulis menjadi,

$$
\begin{aligned}
& \sum_{k=1}^{p-1} \frac{2^{k}}{k}+2 q_{p}(2) \\
& \equiv-\sum_{\substack{k=1 \\
k \text { ganjil }}}^{p-1} p\left(1-p H_{k-1}+p^{2}\left(\frac{\left(H_{k-1}\right)^{2}-H_{k-1,2}}{2}\right)\right)
\end{aligned}
$$




$$
\begin{gathered}
+\sum_{\substack{k=1 \\
k \text { ganjil }}}^{p-1} p\left(p^{3} \frac{\left(\left(H_{k-1}\right)^{3}-3 H_{k-1} H_{k-1.2}\right)}{6}\right) \frac{(-1-1)}{k^{2}} \\
\sum_{k=1}^{p-1} \frac{2^{k}}{k}+2 q_{p}(2) \equiv 2 p \sum_{\substack{k=1 \\
k \text { ganjil } \\
p-1}} \frac{1}{k^{2}} \\
-2 p^{2} \sum_{\substack{k=1 \\
k \text { ganjil } \\
p-1}}^{p-1} \frac{H_{k-1}}{k^{2}}+p^{3} \sum_{\substack{k=1 \\
k \text { ganjil }}} \frac{\left(H_{k-1}\right)^{2}}{k^{2}} \\
-p^{3} \sum_{\substack{k=1 \\
k \text { ganjil }}} \frac{H_{k-1,2}}{k^{2}}\left(\bmod p^{4}\right)
\end{gathered}
$$

Pada persamaan (4.38) ruas kanan suku pertama,

$$
\sum_{\substack{k=1 \\ k \text { ganjil }}}^{p-1} \frac{1}{k^{2}} \equiv \frac{1}{4} \sum_{k=1}^{\frac{(p-1)}{2}} \frac{1}{k^{2}}+\frac{p}{4} \sum_{k=1}^{\frac{(p-1)}{2}} \frac{1}{k^{3}}\left(\bmod p^{2}\right)
$$

Dengan mensubtitusikan persamaan (2.15.1) dan (2.15.3) ke persamaan (4.39) diperoleh,

$$
\begin{aligned}
\sum_{\substack{k=1 \\
k \text { ganjil }}}^{p-1} \frac{1}{k^{2}} & \equiv \frac{1}{4} \cdot \frac{7}{3} p B_{p-3}+\frac{p}{4} \cdot\left(-2 B_{p-3}\right)\left(\bmod p^{2}\right) \\
& \equiv \frac{1}{12} p B_{p-3}\left(\bmod p^{2}\right)
\end{aligned}
$$

Dengan mensubtitusikan persamaan (4.19), (4.30), (4.34) dan (4.40) ke persamaan (4.38) diperoleh,

$$
\begin{aligned}
& \sum_{k=1}^{p-1} \frac{2^{k}}{k}+2 q_{p}(2) \equiv-\frac{7}{12} p^{2} B_{p-3}+p^{3} \sum_{k=1}^{p-1} \frac{H_{k-1}^{2}}{2 k^{2}} \\
& -p^{3} \sum_{k=1}^{p-1} \frac{H_{k-1,2}}{2 k^{2}}\left(\bmod p^{4}\right)
\end{aligned}
$$

Untuk perlu diketahui, langkah demi langkah dalam perhitungannyayaitu menurut teorema Binomial dan identitas pascal yang terdapat pada persamaan (2.15) dan setelah itu dengan menghubungkan persamaan-persamaan pada bilangan Harmonik, dimana bilangan harmonik ini terdapat juga bilangan Bernoulli.
Dengan menggunakan identitas persamaan (2.15) dengan $x=1$ dan $n=p$, untuk suatu $p$ bilangan prima ganjil terdapat teorema Fermat bila diuraikan secara aljabar.Jika disubtitusikan menurut lemma 1 (persamaan (2.24)) baris pertama dengan modulo $p^{4}$, hasil persamaan ini mengandung bilangan Harmonik dan bilangan Bernoulli untuk $p$ suatu bilangan prima ganjil positif, maka hasil akhir kekongruenan dari sisa pembagiannya terdapat sisa berupa negatif.

\section{KESIMPULAN}

Untuk menemukan cara kekongruenan hasil bagi Fermat, terlebih dahulu mencari persamaan pada kombinatorik, identitas pascal, persamaanpersamaan pada bilangan harmonik dan persamaan pada bilangan bernoulli. Sedangkan untuk mencari beberapa kekongruenan pada bilangan harmonik dan bilangan bernoulli untuk modulo $p, p^{2}, p^{2}$, dan $p^{4}$, yaitu dengan selalu melibatkan persamaan kekongruenan bilangan harmonik pada lemma 1 dan lemma 2. Dengan menghubungkan beberapa persamaanpersamaan ini, dan dengan menghubungkan beberapa identitas-identitas dan persamaanpersamaan ini, maka diperoleh persamaan (4.41). Artikel ini, uraiannya masih secara manual atau perhitungan biasa. Disarankan untuk penelitian selanjutnya agar mencoba menemukan modulo $p^{n}$, dimana $n>4$ dengan menggunakan progam komputer.

\section{DAFTAR PUSTAKA}

[1] Http://bimbies.wordpress.com/2014/10/07 /mengapa-allah-swt-suka-dengan-halganjil/amp/ (diakses pada tanggal 07 Oktober 2014).

[2] Ireland, K and Rosen, M. A Classical Introduction to Modern Number Theory, GTM 84, Springer-Verlag, New York Heidelberg Berlin, 1982.

[3] Khongsit, S. and Saikia, P.K. A Congruence For The Fermat Quotient Modulo $p^{3}$. shilong, Meghalaya, India. Integer (2016).

[4] Muhammad, Abdullah. Lubaabut Tafsiir Min Ibni Katsiir (Cet. 1, Jilid 5: Bogor; 
Pustaka Imam asy-syafi'i; Rabi'ul Awwal 1424 H/Mei 2003).

[5] Muhammad, Abdullah. Lubaabut Tafsiir Min Ibni Katsiir (Cet. 1, Jilid 8: Bogor; Pustaka Imam asy-syafi'i; Muharram 1426 H/Februari 2005).

[6] Munir, Rinaldi. Matematika Diskrit, (Edisi Keenam). Penerbit Informatika Bandung. 2016.

[7] Nugroho, Didit B. Diktat kuliah MX 127 Teori Bilangan (Salatiga: Prodi matematika FSM Universitas Kristen Satya Wacana, Desember 2008).

[8] Siang, Jong Jek. Matematika diskrit dan aplikasinya pada ilmu komputer, Penerbit Andi yogyakarta. 2002.

[9] Sun, Z. H. Congruences Involving Bernoulli and Euler Number, J. Number Theori 128 (2008).

[10] Sun, Z. H. Congrunces Concering Bernoulli Number and Bernoulli polynomials, Discrete App. Math. 105 (2000).

[11] Tiro, Muhammad Arif. dkk. pengenalan teori bilangan (Makassar: Andira Publisher, 2008).

[12] Wright, G. H. Hardy E.M. And Introduction to the theory of Numbers, 5th, Oxford Univ. Press, Oxford, 1981, p.104 